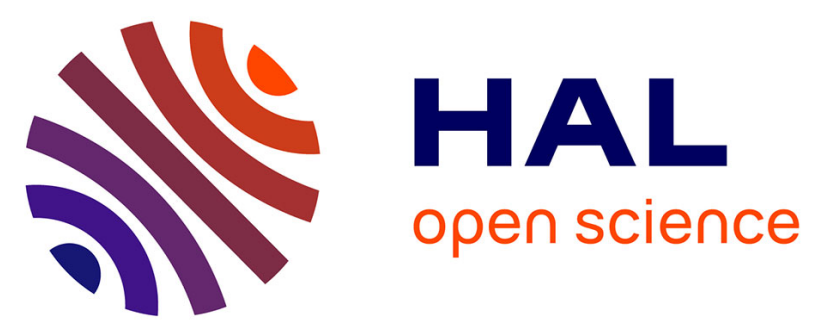

\title{
Switching of excited states in cyclometalated platinum complexes incorporating pyridyl-acetylide ligands (Pt-C[triple bond, length as m-dash]C-py): a combined experimental and theoretical study
}

Camille Latouche, Pierre-Henri Lanoe, J. A. Gareth Williams, Véronique

Guerchais, Abdou Boucekkine, Jean-Luc Fillaut

\section{To cite this version:}

Camille Latouche, Pierre-Henri Lanoe, J. A. Gareth Williams, Véronique Guerchais, Abdou Boucekkine, et al.. Switching of excited states in cyclometalated platinum complexes incorporating pyridyl-acetylide ligands (Pt-C[triple bond, length as m-dash]C-py): a combined experimental and theoretical study. New Journal of Chemistry, 2011, 35 (10), pp.2196-2202. 10.1039/C1NJ20225A . hal-00860209

\section{HAL Id: hal-00860209 https://hal.science/hal-00860209}

Submitted on 10 Sep 2013

HAL is a multi-disciplinary open access archive for the deposit and dissemination of scientific research documents, whether they are published or not. The documents may come from teaching and research institutions in France or abroad, or from public or private research centers.
L'archive ouverte pluridisciplinaire HAL, est destinée au dépôt et à la diffusion de documents scientifiques de niveau recherche, publiés ou non, émanant des établissements d'enseignement et de recherche français ou étrangers, des laboratoires publics ou privés. 


\title{
Switching of excited states in cyclometalated platinum complexes incorporating pyridyl-acetylide ligands ( $\mathrm{Pt}-\mathrm{C} \equiv \mathrm{C}-\mathrm{py})$ : a combined experimental and theoretical study $\dagger \ddagger$
}

\author{
Camille Latouche, ${ }^{a}$ Pierre-Henri Lanoë, ${ }^{a}$ J. A. Gareth Williams, ${ }^{b}$ \\ Véronique Guerchais, ${ }^{a}$ Abdou Boucekkine ${ }^{* a}$ and Jean-Luc Fillaut* ${ }^{a}$ \\ Received (in Gainesville, FL, USA) 10th March 2011, Accepted 31st May 2011 \\ DOI: $10.1039 / \mathrm{c} 1 \mathrm{nj} 20225 \mathrm{a}$
}

This article presents the design of cyclometalated platinum(II) complexes incorporating pyridylappended acetylide ligands of the form $\mathrm{Pt}-\mathrm{C} \equiv \mathrm{C}-$ py, acting either as sites for protonation or methylation reactions or as a host receptor for binding metal cations. The complexes studied are $\mathrm{Pt}\left(t-\mathrm{Bu}_{2} \mathrm{phbpy}\right)(-\mathrm{C} \equiv \mathrm{C}-\mathrm{py}), 2$, which can undergo protonation at the pyridyl $\mathrm{N}$; its cationic $N$-methylated derivative $\left[\operatorname{Pt}\left(t-\mathrm{Bu}_{2} \mathrm{phbpy}\right)(-\mathrm{C} \equiv \mathrm{C}-\text { pyMe })\right]^{+}, \mathbf{4}$, which serves as a model of the $\mathrm{N}$-protonated species; and a derivative in which the pyridyl ring is incorporated into a macrocyclic diamide-crown ether ligand (3). The co-ligand $t$ - $\mathrm{Bu}_{2}$ phbpy is a cyclometalated, $\mathrm{N}^{\wedge} \mathrm{N}^{\wedge} \mathrm{C}$-coordinated phenylbipyridine ligand carrying tert-butyl groups at the 4-positions of the pyridyl rings. The photophysical properties of the neutral compounds $\mathbf{2}$ and $\mathbf{3}$ have been compared to those of the pyridinium, methyl-pyridinium or metal-complexed species (namely $\mathbf{2}-\mathbf{H}^{+}, \mathbf{4}$ and $\mathbf{3}-\mathbf{P b}^{\mathbf{2}}$ ). Detailed TD-DFT calculations provide a theoretical basis to account for the experimentally-observed changes upon protonation/methylation/complexation. The joint TD-DFT and experimental studies provide evidence for an unprecedented molecular switch in the nature of the excited state (from mixed L'LCT/MLCT to ML'CT) in which the acceptor ligand in the $\mathrm{CT}$ process switches from being the $\mathrm{N}^{\wedge} \mathrm{N}^{\wedge} \mathrm{C}$ ligand to the pyridyl acetylide.

\section{Introduction}

Significant work in the field of responsive materials has recently focused on cyclometalated d8 square-planar Pt(II) complexes owing to their photophysical properties: large Stokes' shifts, long emission lifetimes compared to those of purely organic luminophores and the large shifts in emission wavelength maxima that are possible in response to changes in the local environment. ${ }^{1-7}$ Among them, $\left(\mathrm{C}^{\wedge} \mathrm{N}^{\wedge} \mathrm{N}\right) \mathrm{PtX}$ complexes $\left(\mathrm{C}^{\wedge} \mathrm{N}^{\wedge} \mathrm{N}=\right.$ 6-phenyl-2,2'-bipyridine (phbpy), $\mathrm{X}=$ halide, acetylide, etc.) are particularly interesting because of their intense phosphorescent emission. ${ }^{8-13}$ The ability to vary the ancillary ligand $\mathrm{X}$ is an elegant strategy to induce structural modification of the $\left[\left(\mathrm{C}^{\wedge} \mathrm{N}^{\wedge} \mathrm{N}\right) \mathrm{PtX}\right]$ complexes and to

${ }^{a}$ Sciences Chimiques de Rennes, UMR 6226 CNRS-Université de Rennes 1, 35042, Rennes Cedex, France.

E-mail: jean-luc.fillaut@univ-rennes1.fr,

abdou.boucekkine@univ-rennes1.fr; Fax: + 33 (0)2 23236939

${ }^{b}$ Department of Chemistry, University of Durham, South Road,

Durham, DH1 3LE, UK

$\dagger$ This paper is dedicated to Professor Didier Astruc on the occasion of his 65 th birthday.

$\ddagger$ Electronic supplementary information (ESI) available: ESI1experimental details and computational details, TD-DFT results; ESI2-MO diagrams. See DOI: 10.1039/c1nj20225a tune their photophysical properties. In these series, acetylide derivatives ${ }^{9,14-20}$ are of special interest, not only because the strong-field nature of the acetylide ligand can help to augment the emission quantum yield, but also due to the facility with which functionalized terminal aryl-alkynes can be accessed, opening a way to new systems containing a diversity of host receptors. ${ }^{21-31}$ The more electron-withdrawing the group on the phenyl acetylide ligand, the higher the emission energy. This trend is consistent with an assignment of the emission to a triplet metal-to-ligand charge transfer ${ }^{3} \mathrm{MLCT}\left(\mathrm{dPt} \rightarrow \pi^{*} \mathrm{C}^{\wedge} \mathrm{N}^{\wedge} \mathrm{N}\right)$ state, mixed with some acetylide-to-phenylbipyridine ligandto-ligand charge transfer $\left({ }^{3} \mathrm{~L}^{\prime} \mathrm{LCT}\right)$ character. Ancillary acetylide ligands with large electron-withdrawing abilities do not significantly affect the HOMO of the metal center but raise the L'LCT excited-state energy, thus lowering its contribution to the emissive state.

In a previous preliminary contribution, ${ }^{31}$ we described how the complexation of $\mathrm{Pb}^{2+}$ ions into the macrocyclic cavity of complex 3 (Chart 1) resulted in the appearance of a new low-energy band, concomitant with the extinction of the luminescence. These surprising changes were tentatively attributed to an example, unprecedented for cyclometalated $\mathrm{Pt}(\mathrm{II})$ acetylide derivatives, of a switch of CT to the opposite direction upon metal binding, from mixed MLCT/L'LCT to 

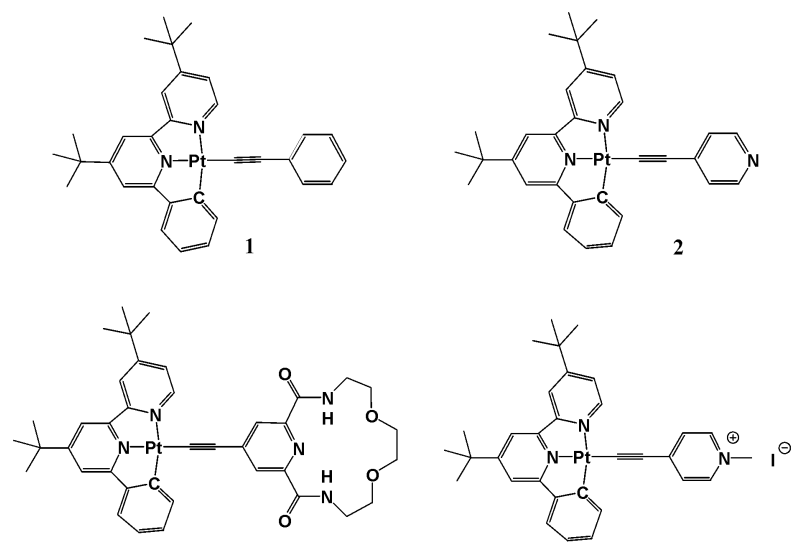

3

Chart 1

ML'CT; in other words, the acceptor ligand in the CT process was thought to change in response to binding of the cation. In the present paper, we describe a joint TD-DFT and experimental study of the protonation of model compound 2 (Chart 1) that allows us to more precisely investigate this process. The characterization of compounds 1-3 and their TD-DFT assignments will be presented, followed by the experimental investigation of the changes in their photophysical properties upon protonation and metal cation binding. These studies highlight the predominant role of the energy levels of the LUMOs in these complexes as the key to tune their emission.

\section{Results and discussion}

The synthesis of compounds $\mathbf{2}$ and $\mathbf{4}$ was carried out using straightforward procedures. Complex $\mathbf{2}$ was prepared starting from $\left[\mathrm{Pt}\left({ }^{\mathrm{t}} \mathrm{Bu}_{2}-\mathrm{C}^{\wedge} \mathrm{N}^{\wedge} \mathrm{N}\right) \mathrm{Cl}\right]^{9}$ and ethynylpyridine, ${ }^{32}$ in the presence of sodium methoxide. It could be converted into 4 upon treatment with a large excess (5 equivalents) of methyl iodide, at room temperature for $24 \mathrm{~h}$. The complete formation of $\mathbf{4}$ was monitored by proton NMR. Compounds $\mathbf{2}$ and $\mathbf{4}$ were obtained as powders and were fully characterized (see ESI $\ddagger$ ).

\section{Photophysical properties of complexes 2-4}

The electronic absorption spectrum of $\mathbf{2}$, in acetonitrile solution, exhibits intense absorption bands at $320-380 \mathrm{~nm}$ and less intense bands at 390-460 nm (Fig. 1; Table 1). With reference to previous spectroscopic work on the platinum(II) phenylbipyridyl complex ${ }^{1,9}$ the high-energy intense absorption bands are assigned to intraligand (IL) transitions of the phenylbipyridine and alkynyl ligands (IL $\left[\mathrm{C}^{\wedge} \mathrm{N}^{\wedge} \mathrm{N}\right]+\mathrm{IL}^{\prime}$ $\left.(-\mathrm{C} \equiv \mathrm{C}-\mathrm{Ar}), \pi \rightarrow \pi^{*}\right)$ ( $\mathrm{L}^{\prime}$ represents the acetylide ligand and $\mathrm{L}$ the phenylbipyridine). The bands at $390-460 \mathrm{~nm}$ are assigned to $\left[\mathrm{d} \pi \mathrm{Pt} \rightarrow \pi^{*}\left(\mathrm{C}^{\wedge} \mathrm{N}^{\wedge} \mathrm{N}\right]\right.$ metal-to-ligand charge transfer (MLCT) and $\left[\pi \mathrm{C} \equiv \mathrm{C} \rightarrow \pi^{*} \mathrm{C}^{\wedge} \mathrm{N}^{\wedge} \mathrm{N}\right]$ ligand-to-ligand charge-transfer ( $\left.\mathrm{L}^{\prime} \mathrm{LCT}\right)$ transitions.

The electron-withdrawing effect of the pyridine-containing acetylide ligands does not result in a significant blue-shift of the L'LCT/MLCT-based absorption bands compared to $\mathbf{1} .^{9,19}$ In contrast, the observed $10 \mathrm{~nm}$ blue-shift in the $\mathrm{L}^{\prime} \mathrm{LCT}+$ MLCT absorption band in $\mathbf{3}^{31}$ compared to $\mathbf{2}$ is likely to be the

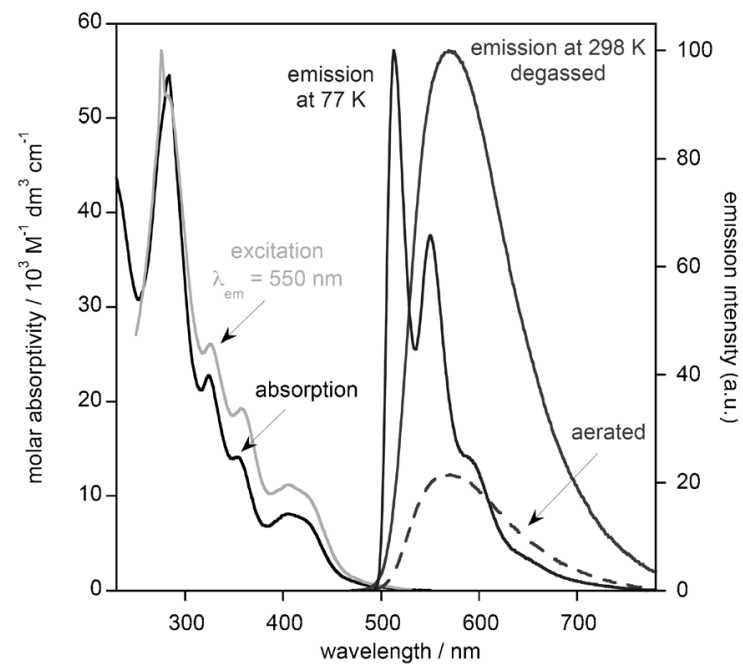

Fig. 1 Electronic absorption (black line) and luminescence excitation $\left(\lambda_{\mathrm{em}}=550 \mathrm{~nm}\right)$ spectra of complex 2 in acetonitrile, and the normalized emission spectra $\left(\lambda_{\mathrm{exc}}=420 \mathrm{~nm}\right)$ under the same conditions and in EPA glass at $77 \mathrm{~K}$.

result of the electron-withdrawing effect of the two amido groups of the macrocycle and/or the presence of hydrogen bonding interactions between pyridine $\mathrm{N}$ and amide $\mathrm{N}-\mathrm{H}$.

The room-temperature emission spectrum of complex $\mathbf{2}$ $\left(\mathrm{CH}_{3} \mathrm{CN}\right.$ solution) exhibits structurally unresolved bands with a maximum at $570 \mathrm{~nm}$ and an emission quantum efficiency of the order of $6 \%$. In accordance with previous studies, ${ }^{9,14-20}$ this emission is assigned to ${ }^{3}$ MLCT excited states to which ${ }^{3} \mathrm{~L}^{\prime} \mathrm{LCT}$ states may also contribute. The emission energy of $\mathbf{2}$ is blue-shifted when compared to that of $\left[\mathrm{Pt}\left({ }^{\mathrm{t}} \mathrm{Bu}_{2}-C^{\wedge} N^{\wedge} N\right)\right.$ $(\mathrm{C} \equiv \mathrm{CPh})] \mathbf{1}\left(\lambda_{\mathrm{em}}=588 \mathrm{~nm}, \mathrm{CH}_{3} \mathrm{CN}\right.$ solution $)$. The corresponding blue-shift in 3 is a little larger $\left(\lambda_{\mathrm{em}}=566 \mathrm{~nm}, \mathrm{CH}_{3} \mathrm{CN}\right.$ solution), qualitatively mirroring the trend in absorption. ${ }^{31}$

\section{Computational studies of complexes 1-3}

DFT calculations (see Computational Details) were performed using the B3LYP functional ${ }^{34-36}$ and a polarized double zeta LANL2DZ basis set, ${ }^{37}$ to model the geometries of complexes 1-3 in the singlet ground-state and the lowest-energy triplet excited state. tert-Butyl groups have been replaced by hydrogen atoms for simplification of the calculations. Solvent $\left(\mathrm{CH}_{2} \mathrm{Cl}_{2}\right.$ or $\mathrm{CH}_{3} \mathrm{CN}$ ) effects have been taken into account using the PCM model. ${ }^{38,39}$

The main optimized geometrical parameters of complexes 1-3 are listed in Table 2. These geometrical parameters are comparable to the experimental values for $\left[\mathrm{Pt}\left(\mathrm{C}^{\wedge} \mathrm{N}^{\wedge} \mathrm{N}\right)\right.$ $(\mathrm{C} \equiv \mathrm{CPh})] .{ }^{9}$ The bond angles of $\mathrm{N} 1-\mathrm{Pt}-\mathrm{N} 1^{\prime}$ and $\mathrm{N} 1-\mathrm{Pt}-\mathrm{C} 3$ are about $77.8^{\circ}$ and $82.0^{\circ}$ for $\mathbf{1}-\mathbf{3}$, corresponding well to the experimental values of $78.4(2)^{\circ}$ and $82.1(2)^{\circ}$ for $\left[\operatorname{Pt}\left(\mathrm{C}^{\wedge} \mathrm{N}^{\wedge} \mathrm{N}\right)\right.$ $(\mathrm{C} \equiv \mathrm{CPh})]^{9}$ and indicating that the coordination geometry of $\mathrm{Pt}(\mathrm{II})$ exhibits nearly square planar conformation. The geometries of 1-3 are quite insensitive to the groups (phenyl, pyridyl or macrocyclic pyridyl) on the acetylide ligand. The calculated $\mathrm{Pt}-\mathrm{N} 1$ and $\mathrm{Pt}-\mathrm{N} 1^{\prime}$ bond lengths range from 2.018 to $2.182 \AA$ corresponding to the experimental values, 1.987(4) and 2.124(4) $\AA$, respectively. ${ }^{9}$ The calculated Pt-C3 bond length

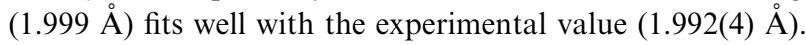


Table 1 Photophysical data for complexes 1-4 in acetonitrile solution at $298 \mathrm{~K}$

\begin{tabular}{lllll}
\hline Compounds & Absorption, ${ }^{a} \lambda_{\text {max }} / \mathrm{nm}\left(\varepsilon / \times 10^{3} \mathrm{~L} \mathrm{~mol}^{-1} \mathrm{~cm}^{-1}\right)$ & Emission,$^{b} \lambda_{\mathrm{em}} / \mathrm{nm}$ & $\Phi_{\text {lum }} \times 10^{2}$ degassed (aerated) $)^{b, c}$ & $\tau / \mathrm{ns}$, degassed $($ aerated $)$ \\
\hline $\mathbf{1}$ & $330(15.5) ; 357(11.0) ; 420(5.85)$ & 588 & $5.0^{9}$ & $800^{9}$ \\
$\mathbf{2}$ & $330(18.6) ; 360(11.8) ; 420(6.6)$ & 570 & $6.3(1.4)$ & $540(95)$ \\
$\mathbf{2}-\mathbf{H}^{+}$ & $360(25.5) ; 395(13.7)$ & 525 & nd & nd \\
$\mathbf{3}$ & $322(23.1) ; 350(13.7) ; 410(7.1)^{31}$ & 566 & $7.3(1.5)$ & $600(105)$ \\
$\mathbf{4}$ & $326(32.5) ; 355(8.5) ; 400(0.1)$ & 549 & $2.9(0.9)$ & $410(110)$
\end{tabular}

${ }^{a}$ Measured in $\mathrm{CH}_{3} \mathrm{CN}$ solution at $298 \mathrm{~K} .{ }^{b}$ Measured in $\mathrm{CH}_{3} \mathrm{CN}$ solution at $298 \mathrm{~K} .{ }^{c}$ Emission quantum yields were determined using $\left[\mathrm{Ru}(\mathrm{bpy})_{3}\right] \mathrm{Cl}_{2}$ in air-equilibrated water $\left(\Phi_{\text {lum }}=0.028\right)^{33}$ as the standard.

Table 2 Optimized geometrical parameters in the gas-phase (distances in $\mathrm{A}$ and angles in deg., experimental values in the solid state determined by X-ray diffraction are given in square brackets) (atom numbering is defined in Fig. S1, ESI $\ddagger$ )

\begin{tabular}{|c|c|c|c|c|}
\hline Complex & $1[\exp ]^{9}$ & 2 & 3 & 4 \\
\hline$\varphi$ & 9.5 [49.9] & 0.1 & 9.1 & 2.2 \\
\hline $\mathrm{Pt} 2-\mathrm{C} 3$ & 1.95 [1.97] & 1.95 & 1.95 & 1.94 \\
\hline $\mathrm{C} 3-\mathrm{C} 4$ & $1.24[1.18]$ & 1.24 & 1.24 & 1.24 \\
\hline $\mathrm{C} 4-\mathrm{C} 5$ & $1.44[1.45]$ & 1.43 & 1.43 & 1.42 \\
\hline $\mathrm{N} 1-\mathrm{Pt} 2-\mathrm{C} 3$ & $101[102]$ & 102 & 103 & - \\
\hline $\mathrm{Pt} 2-\mathrm{C} 3-\mathrm{C} 4$ & 178 [177] & 177 & 179 & - \\
\hline $\mathrm{C} 3-\mathrm{C} 4-\mathrm{C} 5$ & $178[178]$ & 179 & 178 & - \\
\hline $\mathrm{C} 4-\mathrm{C} 5-\mathrm{C} 6$ & $121[121]$ & 122 & 121 & - \\
\hline
\end{tabular}

Similarly, the computed parameters for the acetylide ligand in 1-3 agree reasonably well with the values for $\left[\mathrm{Pt}\left(\mathrm{C}^{\wedge} \mathrm{N}^{\wedge} \mathrm{N}\right)(\mathrm{C} \equiv \mathrm{CPh})\right]{ }^{9}$ As observed for other similar systems, the computed $\mathrm{C} \equiv \mathrm{C}$ distances are longer than the X-ray one (1.24 $\AA$ vs. 1.184(7) $\AA$ ), while the calculated Pt-C distances of $1.95 \AA$ are slightly shorter than the experimental value $(1.970(5) \AA)$. The differences for the computed $\varphi$ dihedral angles (Fig. S1, ESI $\ddagger$ ) formed by the metallacycle $\mathrm{Pt}-\mathrm{N} 1-\mathrm{N} 1^{\prime}$ and the phenyl or pyridyl rings for $\mathbf{1 - 3}$, and the experimental values (from $0.1^{\circ}$ to $9.5^{\circ} \mathrm{vs} .49 .9^{\circ}$ ) can be attributed to packing effects in the crystal structure of $\left[\mathrm{Pt}\left(\mathrm{C}^{\wedge} \mathrm{N}^{\wedge} \mathrm{N}\right)(\mathrm{C} \equiv \mathrm{CPh})\right] .{ }^{9}$ Furthermore, the rotation barrier around the $\mathrm{Pt} 2-\mathrm{C} 3-\mathrm{C} 4-\mathrm{C} 5$ axis is low. Indeed the energy difference between the conformations of 1 at $\varphi=9.5^{\circ}$ and $\varphi=49.9^{\circ}$ was estimated to be less than $0.2 \mathrm{kcal} \mathrm{mol}^{-1}$.

On the basis of the optimized structures in the ground state, the spectroscopic properties related to absorption in acetonitrile were obtained using TD-DFT calculations at the same level of theory. As depicted in Table 3, the HOMO (Highest Occupied Molecular Orbital) and LUMO (Lowest Unoccupied Molecular Orbital) of 1-3 exhibit considerable similarities. In this table are also given the energies of the frontier orbitals and the dipole moments of these complexes.

The HOMOs of 1, 2 and $\mathbf{3}$ are combinations of the $\mathrm{Pt}(\mathrm{II}) \mathrm{d}_{y z}$ orbital (respectively $15 \%(\mathbf{1}), 22 \%$ (2) and $22 \%(3))$ and the $\pi(\mathrm{C} \equiv \mathrm{CPh})$ orbital (respectively $77 \%(1), 69 \%(2)$ and $66 \%$ (3)). The LUMOs of these neutral complexes are mainly

Table 3 Computed properties of complexes 1-4

\begin{tabular}{lllll}
\hline Complex & HOMO energy & HOMO-LUMO gap & Dipole moment/D
\end{tabular}

1

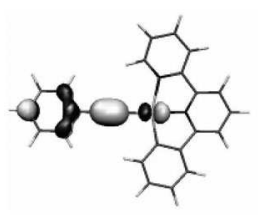

$-5.47$

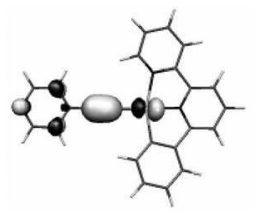

$-5.85$

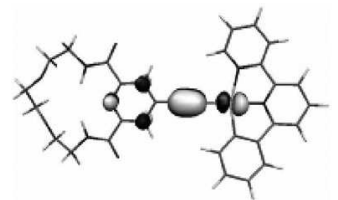

$-6.05$

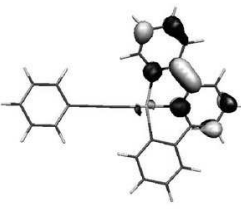

$-2.66$

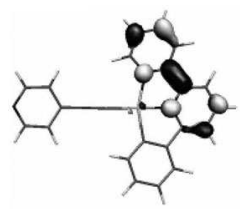

$-2.72$

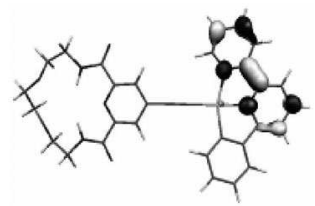

$-2.75$
13.7

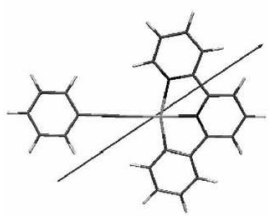

17.7

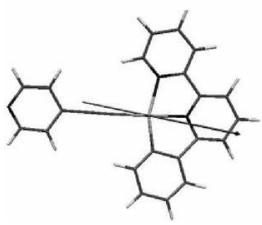

10.5

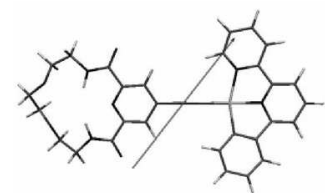


localized (about $82 \%$ (2)) on the bipyridine part of the $\mathrm{C}^{\wedge} \mathrm{N}^{\wedge} \mathrm{N}$ moiety. Therefore, lowest-lying absorptions can be attributed to combined $\left[\pi(\mathrm{C} \equiv \mathrm{C}) \rightarrow \pi^{*}\left(\mathrm{C}^{\wedge} \mathrm{N}^{\wedge} \mathrm{N}\right)\right]$ ligand-to-ligand charge-transfer $\left(\mathrm{L}^{\prime} \mathrm{LCT}\right)$ and $\left[\mathrm{d} \pi(\mathrm{Pt}) \rightarrow \pi^{*}\left(\mathrm{C}^{\wedge} \mathrm{N}^{\wedge} \mathrm{N}\right)\right]$ metalto-ligand charge transfer (MLCT) transitions, if these HOMO to LUMO transitions are allowed. The replacement of the phenyl group on the acetylide ligand $\mathrm{L}^{\prime}$ by the more electronwithdrawing pyridine-containing groups in $\mathbf{2}$ and $\mathbf{3}$ leads to a stabilisation of the HOMOs in $\mathbf{2}$ and $\mathbf{3}(0.4 \mathrm{eV}(\mathbf{2}) ; 0.6 \mathrm{eV}(\mathbf{3}))$. Conversely, the energy level of the LUMOs remains essentially unchanged (from $-2.66 \mathrm{eV}$ for $\mathbf{1}$ to -2.72 and $-2.75 \mathrm{eV}$ for $\mathbf{2}$ and 3 respectively). Thus, the HOMO-LUMO gap increases by $c a .0 .3$ to $0.5 \mathrm{eV}$ from 1 to 2 and $\mathbf{3}$.

The TD-DFT calculations (see ESI $\ddagger$ ) fully confirm the assignment of the lowest-energy observed absorption band. The computed wavelengths at, respectively, 483, 444 and $438 \mathrm{~nm}$ correspond to the observed absorptions at 455,430 and $410 \mathrm{~nm}$ for complexes $\mathbf{1}, \mathbf{2}$ and $\mathbf{3}$ respectively. The corresponding transitions are HOMO-LUMO ones for the three complexes, the nature of the singlet excited state being

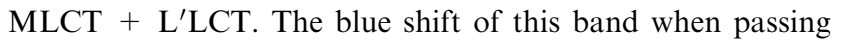
from $\mathbf{1}$ to $\mathbf{2}$ and $\mathbf{3}$ was expected on the basis of the energies of the involved MOs (Table 2) and is correlated to the electronwithdrawing character of the pyridyl ligand.

\section{Protonation and methylation of complex 2: an experimental study}

Protonation of the pendant pyridyl groups of $\mathbf{2}$, by adding aliquots of $\mathrm{CF}_{3} \mathrm{CO}_{2} \mathrm{H}$ (up to 7 equivalents) to a $5.5 \times 10^{-5} \mathrm{M}$ sample of complex 2 in $\mathrm{CH}_{3} \mathrm{CN}$, results in a blue-shift of the absorption maxima in the $330-400 \mathrm{~nm}$ region and an approximate doubling in the intensity of the band centred at about

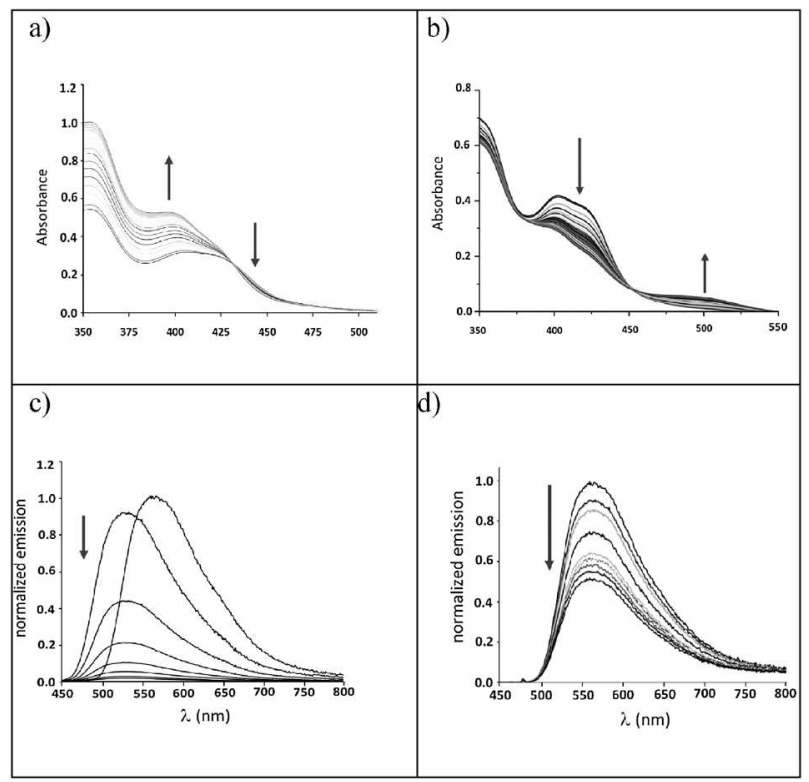

Fig. 2 Changes in the (a) UV/Vis absorption and (c) luminescence spectra of 2 in $\mathrm{CH}_{3} \mathrm{CN}$ solution $\left(5.5 \times 10^{-5} \mathrm{M}\right)$ upon addition of $\mathrm{CF}_{3} \mathrm{CO}_{2} \mathrm{H}$ (up to 7 molar equivalents) $\left(\lambda_{\text {exc }}=430 \mathrm{~nm}\right.$ ). Changes in the (b) $\mathrm{UV} / \mathrm{Vis}$ absorption and (d) luminescence spectra of 3 in $\mathrm{CH}_{3} \mathrm{CN}$ solution $\left(5.7 \times 10^{-5} \mathrm{M}\right.$ ) upon addition of $\mathrm{Pb}^{2+}\left(\mathrm{ClO}_{4}^{-}\right)_{2}$ (up to 3 molar equivalents) $\left(\lambda_{\mathrm{exc}}=450 \mathrm{~nm}\right)$.
$400 \mathrm{~nm}$ (Fig. 2a). This is consistent with the expected formation of a pyridinium unit acting as a stronger electron-withdrawing substituent on $\mathbf{2}-\mathbf{H}^{+}$. Its introduction would be anticipated to substantially stabilise the ethynyl and metal $\mathrm{d}$ orbitals and thereby increase the energy gap between the ground and excited states. Similarly, the methylated complex 4 shows a $30 \mathrm{~nm}$ blue-shift of the absorption bands at $430 \mathrm{~nm}$, compared with the absorption of complex 2 .

The luminescence of $\mathbf{2}$ is blue-shifted from 569 to $525 \mathrm{~nm}$ upon protonation (Fig. 2c). This blue-shift is consistent with an enhancement of the electron-withdrawing character of the ancillary acetylide ligand on $\mathbf{2}$ when protonated, stabilizing both the metal $\mathrm{d}_{\mathrm{Pt}}$ and $\pi_{\mathrm{C} \equiv \mathrm{C}}$ orbitals and thereby increasing the MLCT/L'LCT (respectively ${ }^{3} \mathrm{MLCT} /{ }^{3} \mathrm{~L}^{\prime} \mathrm{LCT}$ ) energy gap.

Similarly, the emission of $4(549 \mathrm{~nm})$ is slightly blue shifted $(20 \mathrm{~nm})$ compared with the absorption of complex $\mathbf{2}$, and its quantum yield is lower ( $\phi=0.02$ compared to 0.05 for 2 ). The emission of $\mathbf{2}$ is even more substantially reduced in intensity upon protonation (by $\sim 90 \%$ after addition of 7 equivalents of $\mathrm{CF}_{3} \mathrm{CO}_{2} \mathrm{H}$ ) (Fig. 2c).

This loss in emission both for $\mathbf{2}-\mathbf{H}^{+}$and for $\mathbf{4}$ is in apparent contradiction of the energy-gap law, ${ }^{40,41}$ which has been shown to apply to $\mathrm{Pt}(\mathrm{II})$ complexes when states of the same orbital parentage are involved. ${ }^{41-44}$ Higher-energy excited states normally display more intense luminescence because there is less likelihood of quenching by low energy molecular vibrations. Thus, that the energy gap law does not hold suggests that the nature of the excited state changes.

The loss in emission for the protonated $\mathbf{2}-\mathbf{H}^{+}$and methylated 4 species could be first explained by the presence of low-lying deactivating metal-centred $\mathrm{d}-\mathrm{d}$ states. Indeed, such $\mathrm{d}-\mathrm{d}$ transitions are known to induce fast non-radiative deactivation, if they are thermally accessible, as they are in complexes with weakfield ligands. ${ }^{45}$ However, the introduction of the strong-field acetylide $^{14}$ and cyclometalating ligands ${ }^{8-13}$ into the coordination sphere of Pt(II) generally helps to push up d-d states to high energies, ${ }^{46}$ and radiationless decay via the $\mathrm{d}-\mathrm{d}$ states becomes less accessible. This explanation therefore appears rather unlikely to account for the loss of emission of $\mathbf{2}-\mathbf{H}^{+}$and $\mathbf{4}$.

Another possible explanation is that protonation of the ethynyl-pyridine ligand leads to the stabilisation of a low-energy $\pi^{*}$ orbital localized on the ancillary alkynyl ligand, which provides an efficient deactivation pathway via equilibration

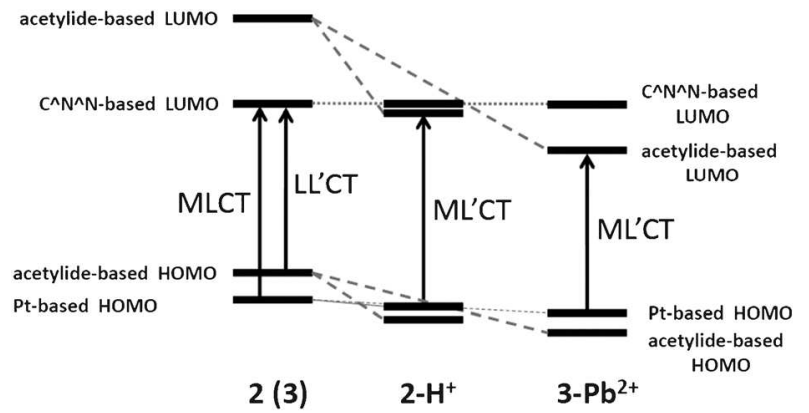

Scheme 1 Proposed qualitative energetic scheme for the switching of the low-lying excited states of $\mathbf{2}$ upon protonation and of $\mathbf{3}$ upon addition of $\mathrm{Pb}^{2+}$ cations. 
Table 4 Frontier MOs of the cationic complexes

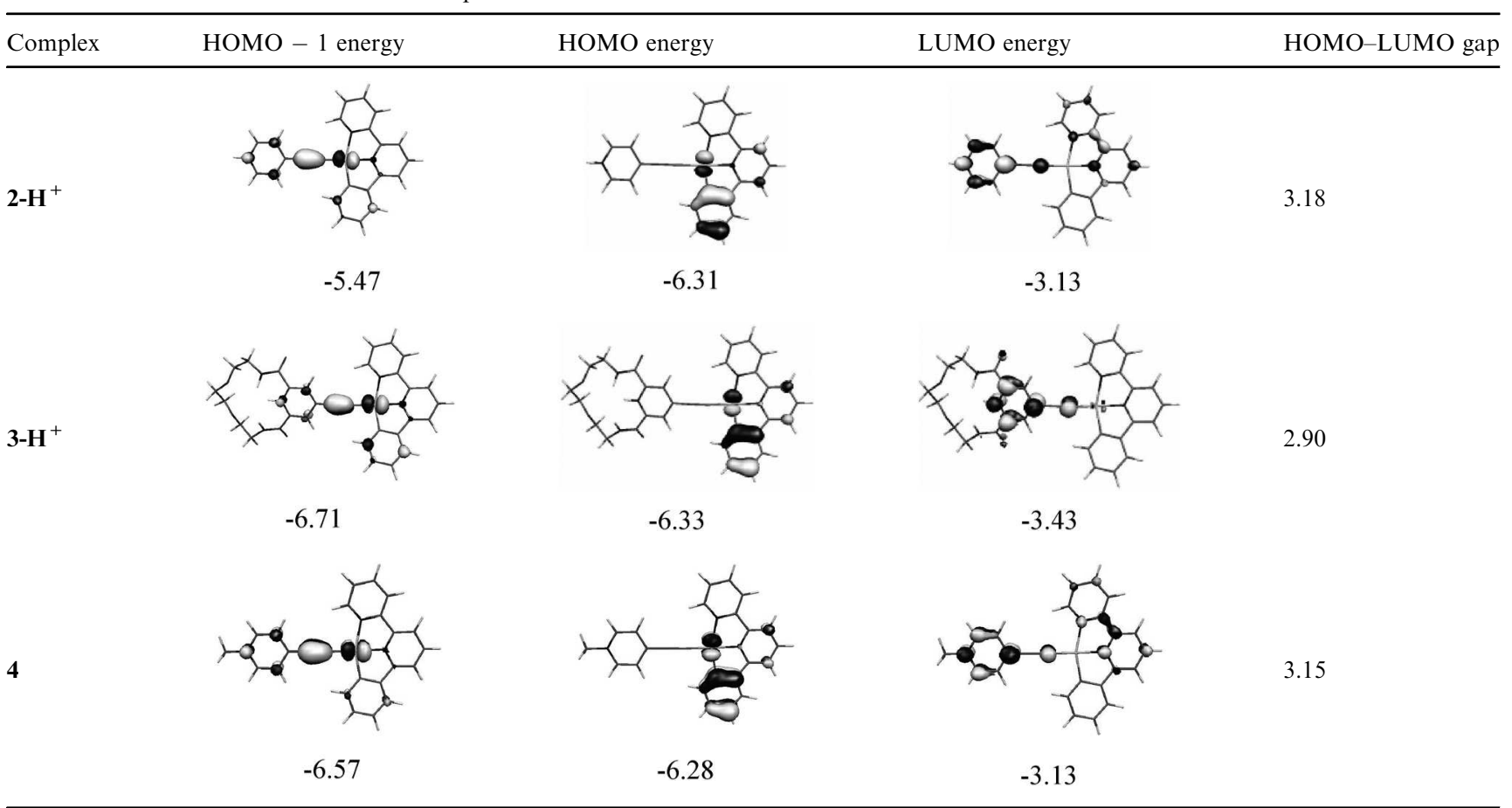

between the "normal" ${ }^{3} \mathrm{MLCT} /{ }^{3} \mathrm{~L}^{\prime} \mathrm{LCT}$ and a short-lived nonradiative ${ }^{3} \mathrm{ML}^{\prime} \mathrm{CT}$ state (Scheme 1 ).

At a first glance, the experimental results for $\mathbf{2}-\mathbf{H}^{+}$appear to contradict those observed for 3 upon binding of $\mathrm{Pb}^{2+}$ cations, ${ }^{31,47}$ Addition of $\mathrm{Pb}^{2+}$ cations, as their perchlorate salts, resulted in significant changes of the absorption spectrum (Fig. 2b). The absorption band at 400-435 nm strongly decreased while a new band centred at $500 \mathrm{~nm}$ concomitantly grew in monotonically. Concomitantly, the luminescence emission intensity of $\mathbf{3}$ decreased, but there was no change whatsoever in the shape or position of the emission spectrum (Fig. 2d). These changes in absorption and emission of $\mathbf{3}$ upon binding of $\mathrm{Pb}^{2+}$ cations were explained by the stabilisation of a low-energy ${ }^{3} \mathrm{ML}^{\prime} \mathrm{CT}\left(\mathrm{dPt} \rightarrow \pi^{*} \mathrm{C} \equiv \mathrm{C}\right)$ state, which would be non-emissive and would compete with the usual ${ }^{3} \mathrm{MLCT}$ $\left(\mathrm{dPt} \rightarrow \pi^{*} \mathrm{C}^{\wedge} \mathrm{N}^{\wedge} \mathrm{N}\right)$ state, mixed with some ${ }^{3} \mathrm{~L}^{\prime} \mathrm{LCT}$ character. ${ }^{31}$

The difference between the experimental behaviours of the $\mathbf{2}-\mathbf{H}^{+}$and $\mathbf{3}-\mathbf{P b}^{\mathbf{2}}$ species may thus be rationalized as the result of a stronger electron-withdrawing effect of the macrocyclic-pyridine, where the two amido units involved in the complexation of $\mathrm{Pb}^{2+}$ cations will reinforce its electronwithdrawing character (Scheme 1).

\section{Protonation and methylation: computational studies for complexes $2-\mathrm{H}^{+}, 3-\mathrm{H}^{+}$and 4}

DFT and TD-DFT calculations were carried out with the goals of establishing the electronic structure of the cationic complexes $\mathbf{2}-\mathbf{H}^{+}$and $\mathbf{4}$, and understanding their photophysical properties. Calculated $\mathbf{3}-\mathbf{H}^{+}$was considered as a simplified model for this species. ${ }^{47}$ Both the absorption and emission wavelengths were compared with the available experimental data $\left(\mathbf{2}-\mathbf{H}^{+}\right.$and $\left.\mathbf{4}\right)$.
The computed geometry for complexes $\mathbf{2}-\mathbf{H}^{+}, \mathbf{3}-\mathbf{H}^{+}$and $\mathbf{4}$ is similar to that of the parent complexes 1-3. The main difference is in the values of the dihedral angle $\varphi$, which are close to zero, except for $\mathbf{3}-\mathbf{H}^{+}$(22.8 to be compared to $9.1^{\circ}$ obtained for $\left.\mathbf{3}\right)$. The significance of these differences might be attenuated because of the low values for the rotation barrier when varying $\varphi$.

The frontier MOs of the $\mathbf{2}-\mathbf{H}^{+}, \mathbf{3}-\mathbf{H}^{+}$and $\mathbf{4}$ species revealed obvious differences from that of the parent complexes 2-3 (Table 4). The HOMOs of $\mathbf{2}-\mathbf{H}^{+}, \mathbf{3}-\mathbf{H}^{+}$and $\mathbf{4}$ are localized on the phenyl moiety of the metallacycle with contributions from the metal, respectively, $22 \%\left(\mathbf{2}-\mathbf{H}^{+}\right), 21 \%\left(3-\mathbf{H}^{+}\right)$and $24 \%(4)$. The acetylide ligand definitely does not contribute to the HOMOs at all. The LUMOs of the $\mathbf{2}-\mathbf{H}^{+}, \mathbf{3}-\mathbf{H}^{+}$and $\mathbf{4}$ species also revealed dramatic changes. For $\mathbf{2}-\mathbf{H}^{+}$and $\mathbf{4}$, the LUMOs are partly localized on the acetylide ligand, with small contribution $(39 \%$ and $40 \%)$ of the bipyridine part of the $\mathrm{C}^{\wedge} \mathrm{N}^{\wedge} \mathrm{N}$. For $3-\mathbf{H}^{+}$, the LUMO is mainly localized on the acetylide ligand, with a small contribution $(4 \%)$ of the metal.

The stabilization of the HOMOs and LUMOs levels in 2-3 upon protonation or methylation results in a dramatically wide redistribution of the MOs. Let us first consider the protonation of $\mathbf{2}$. As expected for cationic species, the energies of the HOMO and LUMO of $\mathbf{2}-\mathbf{H}^{+}$are lower than that of $\mathbf{2}$. The HOMO-LUMO gap remains quasi constant $(3.18 \mathrm{eV}$ instead of $3.13 \mathrm{eV}$ ), but involves MOs whose character differs between $\mathbf{2}$ and $\mathbf{2}-\mathbf{H}^{+}$. The HOMO for $\mathbf{2}$, which arises from a combination of the $\pi(\mathrm{C} \equiv \mathrm{CPh})(69 \%)$ and of the $\operatorname{Pt}(\mathrm{II}) \mathrm{d}_{y z}$ orbital $(23 \%)$, is strongly stabilised $(0.46 \mathrm{eV})$ upon protonation. The HOMO -1 in $\mathbf{2}-\mathbf{H}^{+}$is equivalent to this HOMO of $\mathbf{2}$ Conversely, the HOMO -1 in 2 is less stabilized $(0.25 \mathrm{eV})$ because of a smaller contribution $(0.5 \%)$ of the acetylide ligand. This MO is the counterpart of the HOMO in $\mathbf{2}-\mathbf{H}^{+}$. At the same time, the HOMO -2 in $\mathbf{2}$ which is strongly 
Table 5 Contributions (\%) of the Pt, $\mathrm{C} \equiv \mathrm{CAr}$ and $\mathrm{C}^{\wedge} \mathrm{N}^{\wedge} \mathrm{N}$ units in the LUMOs of $\mathbf{2}-\mathbf{H}^{+}, \mathbf{4}$, and $\mathbf{3}-\mathbf{H}^{+}$

\begin{tabular}{|c|c|c|c|}
\hline & $\begin{array}{l}\mathbf{2 - H ^ { + }} \\
\mathrm{Pt} ; \mathrm{C} \equiv \mathrm{C}-\mathrm{Ar} ; \mathrm{C}^{\wedge} \mathrm{N}^{\wedge} \mathrm{N}\end{array}$ & $\stackrel{4}{\mathrm{Pt}} ; \mathrm{C} \equiv \mathrm{C}-\mathrm{Ar} ; \mathrm{C}^{\wedge} \mathrm{N}^{\wedge} \mathrm{N}$ & $\begin{array}{l}3-\mathrm{H}^{+} \\
\mathrm{Pt} ; \mathrm{C} \equiv \mathrm{C}-\mathrm{Ar} ; \mathrm{C}^{\wedge} \mathrm{N}^{\wedge} \mathrm{N}\end{array}$ \\
\hline LUMO + 3 & & $0 ; 100 ; 0$ & $2 ; 2 ; 96$ \\
\hline LUMO + 2 & $2 ; 5 ; 93$ & $2 ; 5 ; 93$ & $0 ; 100 ; 0$ \\
\hline LUMO + 1 & $4 ; 36 ; 60$ & $4 ; 36 ; 60$ & $4 ; 13 ; 83$ \\
\hline LUMO & $5 ; 56 ; 39$ & $5 ; 54 ; 41$ & $4 ; 84 ; 12$ \\
\hline
\end{tabular}

stabilised $(0.61 \mathrm{eV})$ upon protonation corresponds to the HOMO -2 in $\mathbf{2}-\mathbf{H}^{+}$.

The LUMOs are also fully redistributed upon protonation: the most dramatic effects concern the LUMO and LUMO +1 in $\mathbf{2}-\mathbf{H}^{+}$which correspond to LUMO +3 and LUMO +4 in 2, because of their stabilisation (respectively $1.93 \mathrm{eV}$ and 2.06 $\mathrm{eV})$. This can be related to the important contribution of the acetylide part to these MOs. Conversely, the LUMO +1 in $\mathbf{2}$, whose character is mainly relative to the phenylbipyridine ligand, is less affected $(0.1 \mathrm{eV})$. It is the counterpart of the LUMO +2 in $\mathbf{2}-\mathbf{H}^{+}$. Similar effects are observed for $\mathbf{4}$.

The lowest-lying absorption of $\mathbf{2}-\mathbf{H}^{+}$is attributed to a HOMO -1 to LUMO transition (see ESI $\ddagger$ ). Therefore, the lower-energy absorption corresponds to combined transitions of $\left[\mathrm{d} \pi_{\mathrm{Pt}} \rightarrow \pi^{*} \mathrm{C} \equiv \mathrm{CAr}\right]$ metal-to-ligand charge-transfer (ML'CT) and $\pi_{\mathrm{C}^{\wedge} \mathrm{N}^{\wedge} \mathrm{N}}$ to $\pi^{*}{ }_{\mathrm{C}} \equiv \mathrm{CAr}$ ligand-to-ligand chargetransfer ( $\left.\mathrm{LL}^{\prime} \mathrm{CT}\right)$ transitions. Higher energy absorptions were attributed to ILCT and LLCT combined with MLCT transitions (see ESI $\ddagger$ ). Similar transitions can be attributed in 4. Interestingly, the energy gap of the lowest-lying absorption in $\mathbf{2}-\mathbf{H}^{+}(\mathrm{HOMO}-1 \rightarrow$ LUMO) increases by $0.38 \mathrm{eV}$ in comparison with the HOMO $\rightarrow$ LUMO transition in 2 . Indeed, the absorption wavelength is blue shifted from 444 to $415 \mathrm{~nm}$ whereas the oscillator strength increases from 0.1933 to 0.4194 after protonation, in agreement with the observed increase of the band intensity. This increase is consistent with the experimental blue-shift of the lowestenergy absorptions from $\mathbf{2}$ to $\mathbf{2}-\mathbf{H}^{+}$(respectively from $\mathbf{2}$ to $\mathbf{4}$ ).

The nature of the HOMOs (in particular from HOMO to HOMO - 4) in $\mathbf{3}-\mathbf{H}^{+}$is comparable to that of their analogues in $\mathbf{2}-\mathbf{H}^{+}$. Conversely, the contributions of the $\mathrm{Pt}, \mathrm{C} \equiv \mathrm{CAr}$ and $\mathrm{C}^{\wedge} \mathrm{N}^{\wedge} \mathrm{N}$ fragments in the LUMOs of $3-\mathbf{H}^{+}$significantly differ from those in $\mathbf{2}-\mathbf{H}^{+}$and $\mathbf{4}$ (Table 5). It appears that, in $\mathbf{3}-\mathbf{H}^{+}$, the contributions are quasi totally localized on the $\mathrm{C} \equiv \mathrm{C}-$ Ar fragment (LUMO and LUMO +2 ) or the $\mathrm{C}^{\wedge} \mathrm{N}^{\wedge} \mathrm{N}$ ligand (LUMO +1 and LUMO +3 ), while the distribution is more delocalized in $\mathbf{2}-\mathbf{H}^{+}$and $\mathbf{4}$.

The lowest-lying absorption in $\mathbf{3}-\mathbf{H}^{+}$(see ESI $\ddagger$ ) can be attributed to a combined HOMO - 1 to LUMO transition $(61 \%)$ combined with some HOMO - 2 to LUMO $(22 \%)$, with the average contribution of the $\mathrm{Pt}$ and $-\mathrm{C} \equiv \mathrm{C}$ moiety estimated to be $78 \%$, resulting in a complex ML'CT + $\mathrm{L}^{\prime} \mathrm{L}^{\prime} \mathrm{CT}$ excited state. The energy gap of this lowest-lying absorption decreases by $0.2 \mathrm{eV}$ in comparison with the HOMO $-1 \rightarrow$ LUMO transition in $\mathbf{2}-\mathbf{H}^{+}$. This decrease is mainly due to the stronger stabilisation of the LUMO in $\mathbf{3}-\mathbf{H}^{+}(-0.3 \mathrm{eV})$, while the energy levels of the HOMO - 1 remain comparable $\left(-6.713 \mathrm{eV}\right.$ in $\mathbf{3}-\mathbf{H}^{+} v s$. $-6.642 \mathrm{eV}$ in $\mathbf{2}-\mathbf{H}^{+}$). This could be related to the presence of the $\mathrm{C}=\mathrm{O}$ units in the macrocyclic pyridyl acetylide ligand that
Table 6 Comparison of phosphorescence wavelengths

\begin{tabular}{llllll}
\hline Complex & $\mathbf{1}$ & $\mathbf{2}$ & $\mathbf{2 - \mathbf { H } ^ { + }}$ & $\mathbf{3}$ & $\mathbf{4}$ \\
\hline Experimental (nm) & 588 & 570 & 525 & 566 & 549 \\
Theoretical (nm) & 578 & 564 & 543 & 559 & 551 \\
\hline
\end{tabular}

will reinforce the electron-withdrawing effect in this ligand. Interestingly, the $\mathrm{ML}^{\prime} \mathrm{CT}$ contribution to the excited state increases from $\mathbf{2}-\mathbf{H}^{+}$to $\mathbf{3}-\mathbf{H}^{+}$, while the $\mathrm{L}^{\prime} \mathrm{L}^{\prime} \mathrm{CT}$ contribution decreases by $6 \%$. This effect would be even more sensitive in the case of the complexation of lead cations, leading to a low energy absorption band with an enhanced $\mathrm{ML}^{\prime} \mathrm{CT}$ character, in agreement with the experimental results observed for $\mathbf{3}-\mathbf{P b}^{\mathbf{2}}$.

\section{Phosphorescence emission: a TD-DFT study}

The geometries of all complexes in their triplet states have been optimized and were found to be almost unchanged relatively to the ground state. On the basis of the triplet state optimized geometries, the spectroscopic properties related to phosphorescence, i.e. emitted wavelengths in acetonitrile, were estimated using TD-DFT (see ESI $\ddagger$ ).

The computed phosphorescence wavelengths (Table 6), which fit well with the experimental data, correspond to emission from a triplet state with a main component HOMO -1 to LUMO excited configuration (percentage composition of the triplet state between $62-63 \%$ for the neutral complexes and $59-61 \%$ for the cations). The LUMO is mainly localized on $\mathrm{L}$ for complexes 2 and 3 (90-89\%) but exhibits a higher $\mathrm{L}^{\prime}$ character, i.e. $56 \%$ and $54 \%$, respectively, for $\mathbf{2}-\mathbf{H}^{+}$and $\mathbf{4}$, whereas the percentage composition of $\mathrm{L}$ decreases to $39 \%$ and $41 \%$ respectively. This effect is even more sensitive for 3- $\mathbf{H}^{+}$, which exhibits a contribution from $\mathrm{L}^{\prime}$ of $89 \%$.

The $\mathrm{d}-\mathrm{d}$ excited states remain thermally inaccessible to the CT transitions in $\mathbf{2}-\mathbf{H}^{+}, \mathbf{4}$ and $\mathbf{3}-\mathbf{H}^{+}$, computed TD-DFT absorption energies leading to these $\mathrm{d}-\mathrm{d}$ states being of the order of 4.80-4.90 eV for all complexes. Thus, the impact of either the protonation of $\mathbf{2}$ or the coordination of lead cations to the macrocyclic pyridine in $\mathbf{3}$ is not sufficient for exchanging the energy levels of the $\mathrm{d}-\mathrm{d}$ and CT states in the complexes $\mathbf{2}-\mathbf{H}^{+}, \mathbf{3}-\mathbf{H}^{+}$and $\mathbf{4}$, or for introducing such a pathway of non-radiative decay. Indeed, the energy of the $\mathrm{d}-\mathrm{d}$ states is much higher than those of the MLCT, L'LCT and ML'CT transitions.

\section{Conclusions}

The photophysical properties of the neutral cyclometalated platinum complexes $\mathbf{2}-\mathbf{3}$ incorporating pyridyl-acetylide ligands were compared to those of the protonated, $N$-methylated or metal-complexed species, namely $\mathbf{2}-\mathbf{H}^{+}, \mathbf{4}$ and $\mathbf{3}-\mathbf{P b}^{\mathbf{2}}$. 
These processes resulted in the appearance of new low-energy bands, tentatively assigned to $\left[\mathrm{d} \pi(\mathrm{Pt}) \rightarrow \pi^{*}(\mathrm{C} \equiv \mathrm{C}-\mathrm{py})\right]$ $\mathrm{ML}^{\prime} \mathrm{CT}$ transitions, and leading to a concomitant reduction in the luminescence intensity. TD-DFT calculations were performed in order to provide a theoretical basis to account for these changes. The calculations reveal that the lowest-lying absorptions for $\mathbf{2}$ and $\mathbf{3}$ result from combined L'LCT and MLCT transitions. The nature of the lowest energy phosphorescence is attributed to a combination of ${ }^{3} \mathrm{~L}^{\prime} \mathrm{LCT}$ and ${ }^{3} \mathrm{MLCT}$ transitions. Finally, the impact of the protonation of $\mathbf{2}$ and of the methylation of $\mathbf{2}$ leading to $\mathbf{4}$ at the pyridyl site of the acetylide ligands was examined on the basis of experimental and TDDFT studies. These studies clearly establish that switching of the energy levels of MLCT, $\mathrm{L}^{\prime} \mathrm{LCT}$ and $\mathrm{ML}^{\prime} \mathrm{CT}$ transitions is indeed responsible for the drastic changes observed both in the absorption and phosphorescence properties of the studied compounds.

\section{Acknowledgements}

The authors thank Dr Hubert Le Bozec for fruitful discussions. This research has been supported by the COST D035-0010-05 and PICS CNRS Rennes-Durham.

\section{Notes and references}

1 C.-M. Che, J.-L. Zhang and L.-R. Lin, Chem. Commun., 2002, 2556-2557.

2 N. C. Fletcher and M. C. Lagunas, in Topics in Organometallic Chemistry, ed. H. Le Bozec and V. Guerchais, Springer, Heidelberg, 2010, pp. 143-170.

3 R. McGuire, M. H. Wilson, J. J. Nash, P. E. Fanwick and D. R. McMillin, Inorg. Chem., 2008, 47, 2946-2948.

4 K. M. C. Wong and V. W. W. Yam, Coord. Chem. Rev., 2007, 251, $2477-2488$.

5 Q. A. Zhao, F. Y. Li and C. H. Huang, Chem. Soc. Rev., 2010, 39, 3007-3030.

6 K.-H. Wong, M. C.-W. Chan and C.-M. Che, Chem.-Eur. J., 1999, 5, 2845-2849.

7 H. Guo, M. L. Muro-Small, S. Ji, J. Zhao and F. N. Castellano, Inorg. Chem., 2010, 49, 6802-6804.

8 S. C. F. Kui, I. H. T. Sham, C. C. C. Cheung, C.-W. Ma, B. Yan, N. Zhu, C.-M. Che and W.-F. Fu, Chem.-Eur. J., 2007, 13, 417-435.

9 W. Lu, B.-X. Mi, M. C. W. Chan, Z. Hui, C.-M. Che, N. Zhu and S.-T. Lee, J. Am. Chem. Soc., 2004, 126, 4958-4971.

10 W. Sun, H. Zhu and P. M. Barron, Chem. Mater., 2006, 18, 2602-2610.

11 W. Lu, M. C. W. Chan, N. Zhu, C.-M. Che, C. Li and Z. Hui, J. Am. Chem. Soc., 2004, 126, 7639-7651.

12 P. Shao and W. Sun, Inorg. Chem., 2007, 46, 8603-8612.

13 P. Shao, Y. Li and W. Sun, J. Phys. Chem. A, 2008, 112, $1172-1179$.

14 F. N. Castellano, I. E. Pomestchenko, E. Shikhova, F. Hua, M. L. Muro and N. Rajapakse, Coord. Chem. Rev., 2006, 250, $1819-1828$.

15 W. Lu, B.-X. Mi, M. C. W. Chan, Z. Hui, N. Zhu, S.-T. Lee and C.-M. Che, Chem. Commun., 2002, 206-207.
16 G. S. M. Tong, Y. C. Law, S. C. F. Kui, N. Y. Zhu, K. H. Leung, D. L. Phillips and C. M. Che, Chem.-Eur. J., 2010, 16, 6540-6554.

17 T. J. Wadas, R. J. Lachicotte and R. Eisenberg, Inorg. Chem., 2003, 42, 3772-3778.

18 R. Ziessel, J. B. Seneclauze, B. Ventura, A. Barbieri and F. Barigelletti, Dalton Trans., 2008, 1686-1688.

19 M. L. Clark, S. Diring, P. Retailleau, D. R. McMillin and R. Ziessel, Chem.-Eur. J., 2008, 14, 7168-7179.

20 J. Schneider, P. Du, P. Jarosz, T. Lazarides, X. Wang, W. W. Brennessel and R. Eisenberg, Inorg. Chem., 2009, 48, 4306-4316.

21 H. S. Lo, S. K. Yip, K. M. C. Wong, N. Zhu and V. W.-W. Yam, Organometallics, 2006, 25, 3537-3540.

22 P. K. M. Siu, S.-W. Lai, W. Lu, N. Zhu and C.-M. Che, Eur. J. Inorg. Chem., 2003, 2749-2752.

23 V. W.-W. Yam, K. M.-C. Wong and N. Zhu, J. Am. Chem. Soc., 2002, 124, 6506-6507.

24 Q. Z. Yang, L. Z. Wu, H. Zhang, B. Chen, Z. X. Wu, L. P. Zhang and C. H. Tung, Inorg. Chem., 2004, 43, 5195-5197.

25 Y. Fan, Y.-M. Zhu, F.-R. Dai, L.-Y. Zhang and Z.-N. Chen, Dalton Trans., 2007, 3885-3892.

26 K. M.-C. Wong, W.-S. Tang, X.-X. Lu, N. Zhu and V. W.-W Yam, Inorg. Chem., 2005, 44, 1492-1498.

27 K. Huang, H. Yang, Z. Zhou, H. Chen, F. Li, T. Yi and C. Huang, Inorg. Chim. Acta, 2009, 362, 2577-2580.

28 Q. Z. Yang, Q. X. Tong, L. Z. Wu, Z. X. Wu, L. P. Zhang and C. H. Tung, Eur. J. Inorg. Chem., 2004, 1948-1954.

29 P.-H. Lanoë, J.-L. Fillaut, V. Guerchais, H. Le Bozec and J. A. G. Williams, Eur. J. Inorg. Chem, 2011, 1255-1259.

30 P.-H. Lanoe, J.-L. Fillaut, L. Toupet, J. A. G. Williams, H. L. Bozec and V. Guerchais, Chem. Commun., 2008, 4333-4335.

31 P.-H. Lanoë, H. Le Bozec, J. A. G. Williams, J.-L. Fillaut and V. Guerchais, Dalton Trans., 2010, 39, 707-710.

32 A. S. Kalgutkar and N. Castagnoli, J. Med. Chem., 1992, 35, 4165-4174.

33 K. Nakamaru, Bull. Chem. Soc. Jpn, 1982, 55, 2697.

34 C. Lee, W. Yang and R. G. Parr, Phys. Rev. B: Condens. Matter, 1988, 37, 785.

35 A. D. Becke, J. Chem. Phys., 1993, 98, 5648-5652.

36 P. J. Stephens, F. J. Devlin, C. F. Chabalowski and M. J. Frisch, J. Chem. Phys., 1994, 98, 11623-11627.

37 P. J. Hay and W. R. Wadt, J. Chem. Phys., 1985, 82, 299-310.

38 M. Cossi, G. Scalmani, N. Rega and V. Barone, J. Chem. Phys., 2002, 117, 43-54.

39 V. Barone, M. Cossi and J. Tomasi, J. Chem. Phys., 1997, 107, 3210-3221.

40 R. Englman and J. Jortner, Mol. Phys., 1970, 18, 145-164.

41 J. S. Wilson, N. Chawdhury, M. R. A. Al-Mandhary, M. Younus, M. S. Khan, P. R. Raithby, A. Köhler and R. H. Friend, J. Am. Chem. Soc., 2001, 123, 9412-9417.

42 W. Paw, S. D. Cummings, M. A. Mansour, W. B. Connick, D. K. Geiger and R. Eisenberg, Coord. Chem. Rev., 1998, 171, $125-150$.

43 Q.-Z. Yang, L.-Z. Wu, Z.-X. Wu, L.-P. Zhang and C.-H. Tung, Inorg. Chem., 2002, 41, 5653-5655.

44 M. Hissler, J. E. McGarrah, W. B. Connick, D. K. Geiger, S. D. Cummings and R. Eisenberg, Coord. Chem. Rev., 2000, 208, 115-137.

45 J. A. G. Williams, S. Develay, D. L. Rochester and L. Murphy, Coord. Chem. Rev., 2008, 252, 2596-2611.

46 J. A. G. Williams, Top. Curr. Chem., 2007, 281, 205-268.

47 Addition of $\mathrm{CF}_{3} \mathrm{CO}_{2} \mathrm{H}$ to a solution of 3 in $\mathrm{CH}_{3} \mathrm{CN}$ did not lead to any change in its absorption and emission spectra. This lower sensitivity to acid may be related to the presence of hydrogen bonding interactions between pyridine $\mathrm{N}$ and amide $\mathrm{N}-\mathrm{H}$ in the macrocyclic pyridine system. 